\title{
Comparative Analysis of Methods Employed in Rhodium Recovery
}

\author{
Tejas Suma Shyam ${ }^{a} *$, Hazel Dhruve ${ }^{b}$ \\ ${ }^{a}$ The Education Journey, Vile Parle East, Mumbai - 400055, Maharashtra, India \\ ${ }^{b}$ Institute of Chemical Technology (ICT), Matunga, Mumbai-400019, Maharashtra, India
}

\begin{abstract}
Receive Date: 23 August 2019, Revise Date: 30 September 2019, Accept Date: 12 October 2019
Abstract:

Rhodium is a rare and highly expensive metal with widespread and diverse industrial applications. This makes rhodium recovery and recycling extremely important. Various processes and methods have been developed for rhodium recovery which are very specific to the nature of the application of rhodium. This research study aims at providing a brief yet holistic, classified overview of the many methods that are being employed over the last few decades for rhodium recovery at both laboratory and industrial scale. Specifically, the focus is on the processes employed for recovery of rhodium from waste water, radioactive waste, catalysts, scrap and by leaching with the objective of facilitating a better understanding of such methods. This research study enables researchers to better understand the various processes employed in rhodium recovery.
\end{abstract}

DOI: $10.33945 / \mathrm{SAMI} / \mathrm{JCR} .2019 .4 .4$

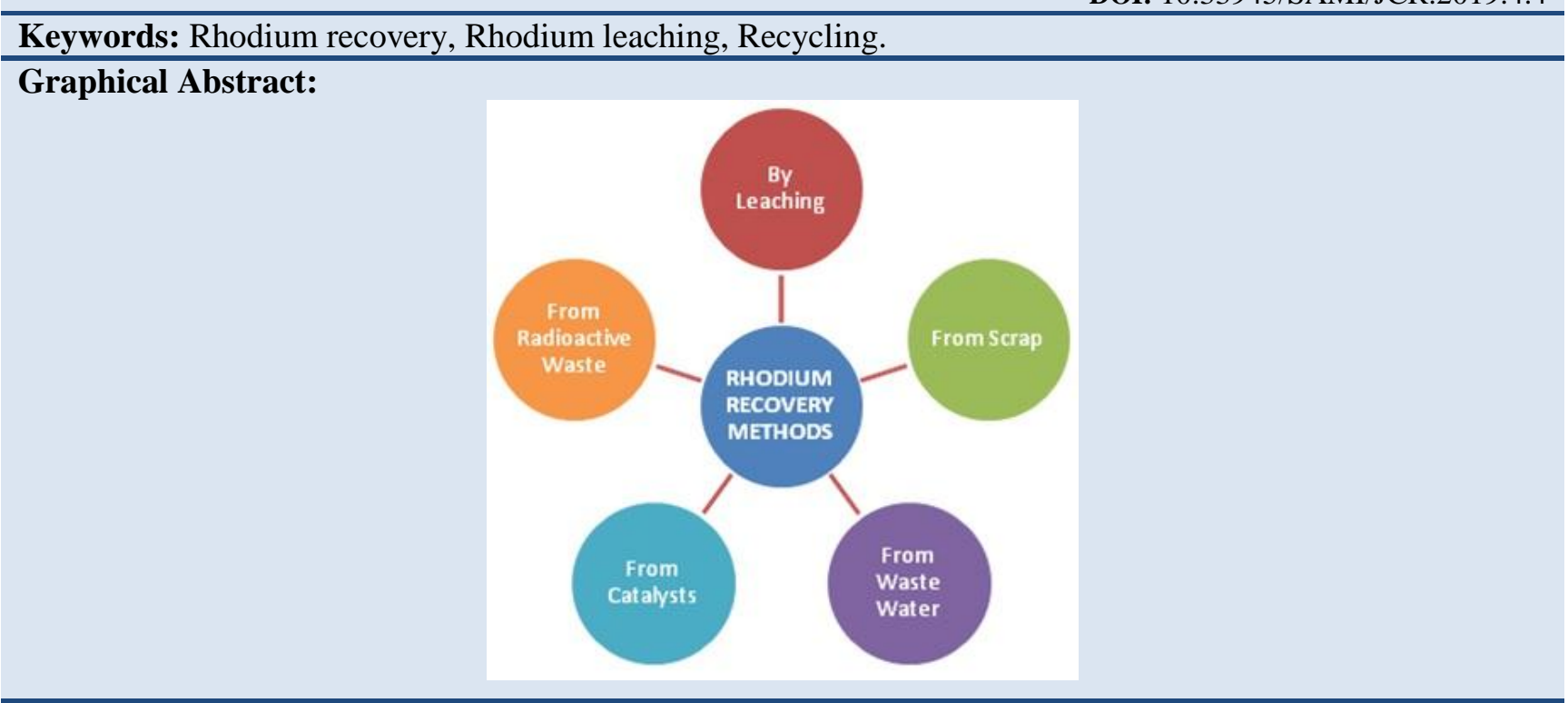

\section{Biography:}

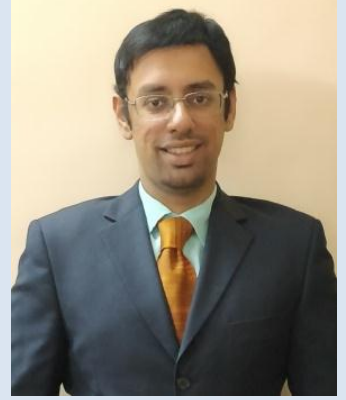

Tejas Suma Shyam is a B. Tech (with Honours) \& M. Tech (both from IIT Bombay). After a brief stint with the corporate world at the beginning of his career, he decided to take a full-time plunge to pursue his passion - Teaching. He started his own institute called "TEJ - The Education Journey" in Mumbai, India where he has been teaching, mentoring and guiding students from the age group from Grade 7 till $2^{\text {nd }}$ Year Engineering in Physics, Chemistry and Mathematics for various competitive and non-competitive exams. He is also a Corporate Consultant to companies in the Metals and Materials Science domain. A TEDx speaker, his speech on "Education is not equal to information" has been well received. 


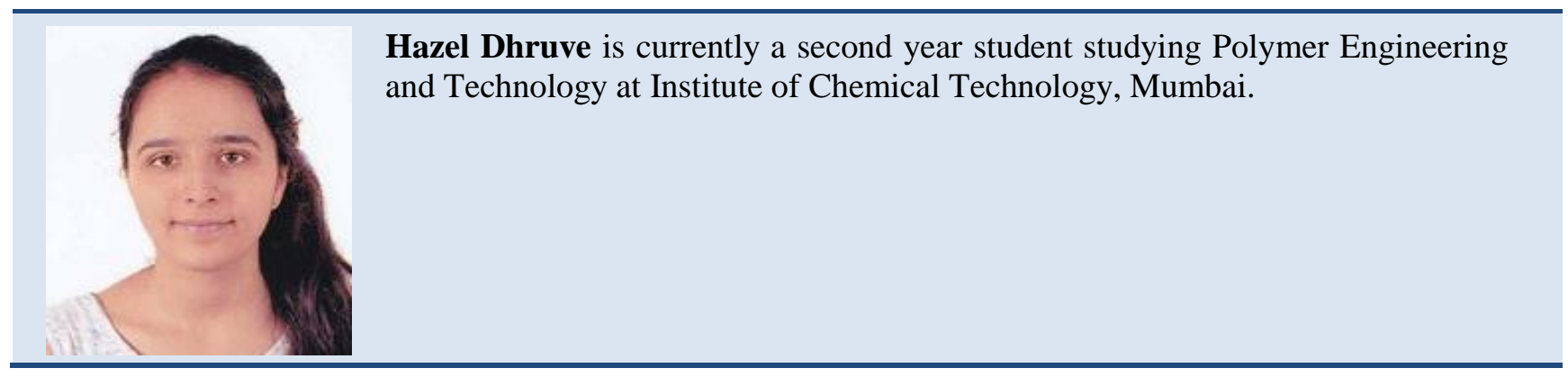

\section{Introduction}

Rhodium is one of the rarest elements in the earth's crust [1] and has found a wide range of applications, especially in plating. The use of rhodium salts for electro deposition due to reflectivity, anti-tarnish properties and wear resistance of the rhodium deposit is well known in jewellery, electronics, and industrial applications [2-4]. Immersion plating of rhodium is also carried out to provide adherent and wear resistant coatings [5].

Many scientific applications of rhodium and rhodium plating exist. It is used in electrothermal atomic absorption spectrometry [6] and extensively used in catalysis in organic chemistry [7-10]. The use of platinum-rhodium based catalysts in automobile catalytic converters is notable [10].

The price of rhodium is higher than platinum and palladium [11]. Thus, rhodium is not only a rare element but also highly expensive.

Thus, given the rarity and high cost of rhodium, it is critical that used rhodium be recovered and recycled for use [12]. Since rhodium is used in a diverse range of applications, recovery processes are often complex and specific to the type of application.

In this review paper, we will briefly describe the most common processes, techniques and methods of rhodium recovery. Motivation for this review was to present a holistic idea regarding the current scenario so that newer, cheaper and better methods may possibly be developed by identifying shortcomings, if any, in the current methods. In the recent past, there has been no consolidated review on the rhodium recovery techniques. This review aimed to cover and classify rhodium recovery techniques developed and implemented over the last few decades, with specific focus on recovery from waste water, radioactive waste, catalysts, scrap, and by leaching. Although this review is not a comprehensive list of methods, owing to the wide range of rhodium applications and the specific nature of recovery processes associated with them, it does provide a concise overview of many of the commonly used methods.

\section{Recovery techniques}

\subsection{Recovery from Wastewater}

Cementation using zinc powder is one of the common methods utilized to recover rhodium from rinsing water. Given that such rinsing water usually also contains free acid and the rhodium in complex form, the amount of zinc required is relatively high since it shoud also react with the free acid before cementation can occur. Elevated temperatures and mechanical agitation are also the necessary requirements [13].

Spent rhodium sulphate plating solutions are also commonly encountered. In such cases, rhodium is cemented out of the solution by heating it with powdered zinc. Zinc content, reaction time, reaction temperature, $\mathrm{pH}$ of solution and mechanical agitation affect the whole process. The procedure requires temperature to be $45^{\circ} \mathrm{C}, \mathrm{pH}$ of $1.5,50 \mathrm{mg}$ of zinc powder and $60 \mathrm{~min}$ for completing the reaction [14]. While removing rhodium from aqueous solutions and industrial effluents, rhodium speciation is one of the most important factors impacting its extraction. Hence, a method to remove rhodium using a sulphate-reducing bacteria (SRB) consortium has been implemented and studied. SRB have greater affinity for the anionic rhodium species and hence $\mathrm{pH}$ control plays a major part in this process. While industrial effluents may have a low $\mathrm{pH}$ and hence will require pre-treatment (thus limiting the utility of this method), SRB based enzymatic rhodium recovery seems to still be a viable option [15].

\subsection{Recovery by Leaching}

The process of leaching of 'Platinum Group Metals' (PGMs) is a common way of separating them from acidic solutions that contain large amount of lead, aluminum, iron and cerium. In one method, a column of Amberlite IRA-93 anion-exchange resin is used to recover platinum metals from the solution. Selective stripping of these metals from the resin is the next step, wherein rhodium can be further separated by eluting it first with $6.0 \mathrm{M}$ hydrochloric acid. An optimum temperature of $70{ }^{\circ} \mathrm{C}$ has been proposed. This method has been reported to be suitable for analytical and larger scale operations due to its simplicity, safety, and economical implementation [16].

In general, $\mathrm{HCl}$ and aqua regia are supposed to be suitable to leach more than $90 \%$ of $\mathrm{Pd}, \mathrm{Pt}, \mathrm{Rd}$ and $\mathrm{Rh}$ at high temperatures [17]. However, it is difficult to 
obtain complete dissolution of rhodium with just high temperature. Recently, an optimized method has been developed for dissolving rhodium in aqua regia at 220 ${ }^{\circ} \mathrm{C}$ for 24 hours which allows for complete rhodium dissolution [18].

Recovery of PGMs and their concentration and isolation using leaching is an area of considerable interest, especially from sulphide ores with a low sulphide content. Post leaching, usage of sorption with new kinds of sorbents that allow for better separation of PGMs from other metals is one of the more efficient methods used for PGM recovery. Rhodium recovery can be carried out from hydrochlorination solutions using ion exchange sorption with sorbents such as Anionite Rossion-11. The solution should ideally not contain more than $125 \mathrm{~g} / \mathrm{L}$ of $\mathrm{HCl}$ and not more than $15 \mathrm{~g} / \mathrm{L}$ of $\mathrm{Fe}^{3+}$ ions if efficient recovery is desired. Rhodium recovery also tends to decrease if sinter hydrochlorination time reduces as rhodium has a tendency to exist in many different complex forms such as $\left[\mathrm{RhCl}_{6}\right]^{2-}$ and $\left[\mathrm{RhCl}_{6-\mathrm{x}}(\mathrm{H} 2 \mathrm{O})_{\mathrm{x}}\right]^{\mathrm{x}-3}$ which do not get sorbed easily. In general, recovery of PGMs is found to increase when a two-stage leaching in counter current mode is employed [19].

Nitrogen sorbents generally are nowadays preferred for PGM recovery from solutions due to their high absorption and good kinetic properties. As such, even trace amounts of these metals can be recovered from solutions that even have high salt content of nonferrous and other metals [20].

\subsection{Recovery from Catalysts}

The distillation of hydroformylated products from the reaction of unsaturated hydrocarbons or fatty acids leaves a residue of soluble rhodium materials. This residue can be mixed with an inert catalyst support, volatilized and carbonized at elevated temperatures to separate the organic matter by breaking it down finally to carbon. The carbon combines with a stream of air to convert into carbon dioxide, and any hydrogen is then converted to water. Rhodium, along with the inert catalyst, is left behind [21].

Another common catalyst used is rhodium in metallic or compound form alongwith water soluble phosphines. To recover the rhodium, an acid is added to this catalyst and the solution is reacted with an amine solution stage-wise in an organic solvent. Further addition of inorganic base such as sodium hydroxide or potassium carbonate followed by mixing causes removal of impurities such as iron and halides. Rhodium can be precipitated by addition of elemental sulphur, but this must be reprocessed before use [22]

\subsection{Recovery from Scrap}

Hydrometallurgical and pyrometallurgical processes on electronic scrap [23], effect of $\mathrm{Al}_{2} \mathrm{O}_{3}$ and $\mathrm{MgO}$ on the dissolution of rhodium in slag [24], and use of metal vapour [25], are few ways to recover rhodium from scrap.

Pyrometallurgical processing for recovery of rhodium uses an input of industrial waste and by-products from the non-ferrous industry and involves pumping of oxygen with coke into a molten bath containing lead, tin and copper as base metals. Smelting causes precious metals such as rhodium and platinum to separate out from the remaining metals. The remaining metals form a slag with lead [26].

Fire assaying can also be employed to separate rhodium from other base metals. In this method, rhodium can be efficiently collected in a copper-nickel-iron button using the wet method for analysis of the button. Upon completion of the dissolution procedure using concentrated hydrochloric acid and nitric acid, rhodium can be separated from the base metals by cation exchange [27].

Another variation of the combination of fire assay and wet button method involves using lead and perchloric acid. The sample is fused with these materials and heated to around $190{ }^{\circ} \mathrm{C}$. Then the PGMs are precipitated out due to reduction by formic acid. This wet analysis method is much more reliable and effective compared with that of cupellation, for the separation of rhodium from the base metals [28].

Rhodium can also be recovered from the slag of sodium oxide and silicon oxide. The components of the slag such as alumina, magnesium oxide and copper oxide affect this process. It has been reported that when the ratio of $\mathrm{Na}_{2} \mathrm{O} / \mathrm{SiO}_{2}$ is fixed at 0.97 , the solubility of rhodium in slags decreases with increase in alumina and magnesia. However, the solubility slightly increases with increasing content of $\mathrm{CuO}_{\mathrm{x}}$. The assumption is that rhodium in slags is present as $\mathrm{RhO}_{1.5}$ [24]. Rhodium exhibits an acidic character in the slag and its solubility can be decreased by lowering the basic oxide content of the slag [29]. The 'rhodate capacity' which is the dissolution behaviour of rhodium in molten slag, depends on the basicity. This principle can be also used to determine the content of rhodium in the slag [24].

The "catalyst scrap" is rare and costly [30]. A recently developed technique allows for rhodium recovery from scrap. This technique makes use of vapours of reactive metals like magnesium and calcium. This seems to give higher dissolution efficiency for rhodium [25]. Rhodium recovered from the scrap through smelting needs to be dissolved in an acid. This is a challenging process since rhodium is mostly inert. Even though many techniques such as leaching with oxidants or $\mathrm{HCl}$ leaching have been used, they have failed at giving the required dissolution rate, and hence become unsuitable for quick rhodium recovery. Thus, to achieve quicker rhodium recovery, the use of reactive vapours has been 
suggested. The experiment takes place in an air tight container and all of the scrap is made to react with the vapour. These metals are particularly used due to their strong affinity for PGMs [30].

\subsection{Recovery from Radioactive Waste}

Low concentration of rhodium (III) species is present in waste solutions derived from the reprocessing of nuclear reactor fuel. In an aqueous, acidic nitrate matrix which undergoes a high degree of radiolysis to convert nitrate to NO, rhodium forms the species $\left[\mathrm{Rh}(\mathrm{NO})_{2}\right]^{3+}$. This can be extracted using Aliquat 336 in suitable concentration in carbon tetrachloride [31].

Nuclear fission products include palladium, rhodium and ruthenium, and can be a valuable source of these three metals. However, their separation from the fuel during reprocessing operations, owing to various process constraints and inherent radioactivity of PGMs, is quite complex and have not found much success outside of laboratories. In thermal reactor fuel, majority of the PGMs are found in the high level liquid waste and solvent extraction methods seem appropriate for extraction of rhodium and palladium [32].

The selection of suitable extraction reagents is done based on speciation and co-ordination chemistry displayed by these elements in nitric acid. Since it has been found that hexanitrito complexes $\left[\mathrm{Rh}\left(\mathrm{NO}_{2}\right)_{6}\right]^{3-}$ of rhodium seem to ultimately get created during the extraction process, these anionic species have been efficiently and rapidly extracted by long-chain aliphatic amines from nitrite/nitric acid systems in the presence of salting-out reagents [32].

Another method for recovery of rhodium from radioactive waste is based on the complete removal of ruthenium from radioactive palladium and rhodium. Decay of $40-\mathrm{d}{ }^{103} \mathrm{Ru}$ yields nonradioactive ${ }^{103} \mathrm{Rh}$. After waiting for an appropriate decay period, the rhodium is separated from the remaining ruthenium using liquid metal extraction and partitioning systems [33].

\section{Conclusion}

This study has examined various methods of rhodium recovery such as recovery from waste water, using leaching, from catalysts, scrap and radioactive waste. These methods are currently being employed at various scales and in diverse industries. Rhodium recovery is important because rhodium is rare and has a diverse set of uses in a variety of industries. As such, due to the different forms in which rhodium gets used, there are a variety of different methods employed to recover rhodium. Across several decades, many methods have been implemented, modified and re-implemented to efficiently recover rhodium. This work aimed to give a brief yet consolidated overview of some methods used to facilitate better understanding of rhodium recovery.

\section{Acknowledgment}

The authors would like to acknowledge the support received from 'The Education Journey', Mumbai, India.

\section{Disclosure statement}

No potential conflict of interest was reported by the authors.

\section{References}

[1] Cardarelli, F. (2008). Materials handbook: a concise desktop reference. Springer Science \& Business Media.

[2] Weisberg, A. M. (1999). Rhodium plating. Metal Finishing, 1(97), 297-301.

[3] Pushpavanam, M., Raman, V., \& Shenoi, B. A. (1981). Rhodium-electrodeposition and applications. Surface Technology, 12(4), 351-360.

[4] Keitel, W., \& Zschiegner, H. E. (1931). Electrodeposition of Platinum, Palladium and Rhodium. Transactions of The Electrochemical Society, 59(1), 273-275.

[5] Johnson, R. W. (1961). Immersion plating of the platinum group metals. Journal of The Electrochemical Society, 108(7), 632-635.

[6] Bulska, E., \& Jędral, W. (1995). Application of palladium-and rhodium-plating of the graphite furnace in electrothermal atomic absorption spectrometry. Journal of Analytical Atomic Spectrometry, 10(1), 4953.

[7] Ojima, I., \& Vidal, E. S. (1998). Rhodiumcatalyzed cyclohydrocarbonylation: Application to the synthesis of (+)-prosopinine and (-)deoxoprosophylline. The Journal of Organic Chemistry, 63(22), 7999-8003.

[8] Hyster, T. K., \& Rovis, T. (2011). An improved catalyst architecture for rhodium (III) catalyzed $\mathrm{C}-\mathrm{H}$ activation and its application to pyridone synthesis. Chemical science, 2(8), 1606-1610.

[9] Jayakumar, J., Parthasarathy, K., \& Cheng, C. H. (2012). One-Pot Synthesis of Isoquinolinium Salts by Rhodium-Catalyzed $\mathrm{C} \square \quad \mathrm{H}$ Bond Activation: Application to the Total Synthesis of Oxychelerythrine. Angewandte Chemie International Edition, 51(1), 197200.

[10] Helmers, E., \& Mergel, N. (1998). Platinum and rhodium in a polluted environment: studying the emissions of automobile catalysts with emphasis on the application of CSV rhodium analysis. Fresenius' journal of analytical chemistry, 362(6), 522-528.

[11] Stankovića, V., \& Comninellisb, C. Rhodium recovery and recycling from spent materials. 
[12] Harjanto, S., Cao, Y., Shibayama, A., Naitoh, I., Nanami, T., Kasahara, K., ... \& Fujita, T. (2006). Leaching of $\mathrm{Pt}, \mathrm{Pd}$ and $\mathrm{Rh}$ from automotive catalyst residue in various chloride based solutions. Materials Transactions, 47(1), 129-135.

[13] Aktas, S. (2011). Rhodium recovery from rhodium-containing waste rinsing water via cementation using zinc powder. Hydrometallurgy, 106(1-2), 71-75.

[14] Morcali, M. H., Zeytuncu, B., \& Yucel, O. (2013). Rhodium cementation from spent plating solution using Taguchi's method. Canadian Metallurgical Quarterly, 52(4), 488-491.

[15] Ngwenya, N., \& Whiteley, C. G. (2006). Recovery of rhodium (III) from solutions and industrial wastewaters by a sulfate-reducing bacteria consortium. Biotechnology progress, 22(6), 1604-1611.

[16] Gaita, R., \& Al-Bazi, S. J. (1995). An ionexchange method for selective separation of palladium, platinum and rhodium from solutions obtained by leaching automotive catalytic converters. Talanta, 42(2), 249-255.

[17] Suoranta, T., Zugazua, O., Niemelä, M., \& Perämäki, P. (2015). Recovery of palladium, platinum, rhodium and ruthenium from catalyst materials using microwave-assisted leaching and cloud point extraction. Hydrometallurgy, 154, 56-62.

[18] Shyam, T., Ajit, A., Jangid, R. (2020),Optimized rhodium dissolution process using aqua regia, Advanced Journal of Chemistry, Section A: Theoretical , Engineering and Applied Chemistry, 3(2),159-164.

[19] Tatarnikov, A. V., Sokolskaya, I., Shneerson, Y. M., Lapin, A. Y., \& Goncharov, P. M. (2004). Treatment of platinum flotation products. Platinum Metals Review, 48(3), 125-132.

[20] Miroshnichenko, A. A. (2016). Sorption recovery of platinum metals from compound solutions. Procedia Engineering, 152, 8-12.

[21] Friedrich, J. P. (1975). U.S. Patent No. 3,899,442. Washington, DC: U.S. Patent and Trademark Office.

[22] Gartner, R., Cornils, B., Bexten, L., \& Kupies, D. (1985). U.S. Patent No. 4,504,588. Washington, DC: U.S. Patent and Trademark Office.
[23] Hoffmann, J. E. (1992). Recovering precious metals from electronic scrap. JOM, 44(7), 43-48.

[24] Wiraseranee, C., Yoshikawa, T., Okabe, T. H., \& Morita, K. (2013). Effect of $\mathrm{Al} 2 \mathrm{O} 3, \mathrm{MgO}$ and $\mathrm{CuOx}$ on the dissolution behavior of rhodium in the Na2O-SiO2 slags. Journal of Mining and Metallurgy B: Metallurgy, 49(2), 131-138.

[25] Kayanuma, Y., Okabe, T. H., Mitsuda, Y., \& Maeda, M. (2004). New recovery process for rhodium using metal vapor. Journal of alloys and compounds, 365(1-2), 211-220.

[26] Hagelüken, C. (2006). Recycling of electronic scrap at Umicore's integrated metals smelter and refinery. Erzmetall, 59(3), 152-161.

[27] Sant, B. R., \& Beamish, F. E. (1961). New fire assay method for rhodium. Analytical Chemistry, 33(2), 304-305.

[28] Diamantatos, A. (1986). Accurate determination of platinum, palladium, gold and silver in ores and concentrates by wet chemical analysis of the lead assay button. Analyst, 111(2), 213-215.

[29] Wiraseranee, C., Okabe, T. H., \& Morita, K. (2013). Dissolution behavior of rhodium in the $\mathrm{Na} 2 \mathrm{O}$ $\mathrm{SiO} 2$ and $\mathrm{CaO}-\mathrm{SiO} 2$ slags. Metallurgical and Materials Transactions B, 44(3), 584-592.

[30] Kayanuma, Y., Okabe, T. H., \& Maeda, M. (2004). Metal vapor treatment for enhancing the dissolution of platinum group metals from automotive catalyst scrap. Metallurgical and Materials Transactions B, 35(5), 817-824.

[31] Hoffman Jr, W. A. (1968). Rhodium Species In Radioactive Waste Solutions (No. ARH-732). Atlantic Richfield Hanford Co., Richland, Wash..

[32] Bush, R. P. (1991). Recovery of platinum group metals from high level radioactive waste. Platinum Metals Review, 35(4), 202-208.

[33] Smith, F. J., \& Mc Duffie, H. F. (1981). Recovery of nonradioactive palladium and rhodium from radioactive waste. Separation Science and Technology, 16(9), 1071-1079.

How to cite this manuscript: Tejas Suma Shyam, Hazel Dhruve, Comparative analysis of methods employed in rhodium recovery, Journal of Chemical Reviews (J. Chem. Rev. ), 2019, 1(4), 282-286. 